\title{
Morphological Analysis of the Carapace of the African Sideneck Turtle (Pelusios castaneus)
}

\author{
Olukole S.G. ${ }^{* 1}$; Okusanya B.O. ${ }^{2}$; Agbato O.A. ${ }^{1}$, Kekere A. D. ${ }^{1}$; \\ Oyeyemi M.O. ${ }^{2}$; Oke B.O.
}

${ }^{1}$ Department of Veterinary Anatomy, Faculty of Veterinary Medicine, University of Ibadan, Ibadan, Nigeria.

2 Department of Veterinary Surgery and Reproduction, Faculty of Veterinary Medicine, University of Ibadan, Ibadan, Nigeria.

\section{Abstract}

The morphological analysis of the carapace of the African sideneck turtle (Pelusios castaneus) was carried out using twenty adult turtles comprising twenty females and forty males picked up at different times in various river banks in Ibadan, Nigeria with the view to providing baseline information that could be useful in the comparative osteology of sea and freshwater turtles as well as in the identification of the shell of the turtle in paleontological and archaeological investigations. The average body weight of the turtles used for the study was $0.82 \pm 0.03 \mathrm{~kg}$. The curved carapace and plastron lengths of the turtles were 26.4 $\pm 1.87 \mathrm{~cm}$ and $19.3 \pm 1.13 \mathrm{~cm}$, respectively. The carapace of the turtles varied from dark brown to dark in colour, had five vertebral, four pairs of costal and twelve pairs of J. Vet. Anat. marginal scutes with the inframarginal scute forming the bridge between the carapace and plastron. The turtle had seven neural bones flanked on each side by eight pairs of pleurals, while eleven pairs of peripheral bones surrounded the pleurals. The basic anatomy of the shell of this animal is similar to those of earlier reports on shell morphology of the chelonians.

Keywords: Carapace, plastron, morphology, scutes, turtle.

\section{Introduction}

The African sideneck turtle (Pelusios castaneus) is a freshwater turtle of the family Pelomedusidae, widely distributed in West Africa, occurring from Guinea and Senegal to northwestern Angola (Kirkpatrick, 1995). The $P$. castaneus is a small to me- 
dium in size, with relatively extensive plastron that may have a hinge present between the pectoral and abdominal scutes (Olukole et al., 2010). The turtle shell has long attracted the attention of comparative anatomists, being comprised of dorsal and ventral moieties, termed the carapace and plastron, respectively (Nagashima et al., 2012).

A conservative life history pattern has enabled chelonians to persist for roughly 200 million years and inhabit terrestrial, fresh water, and marine habitats (Frazer, 2000). This long persistence of chelonians is partly due to the possession of an extremely specialised body wall called the shell comprising discrete bony and epidermal elements. The turtle shell has been considered a textbook example of a morphological novelty (Gilbert et al., 2001). Turtles are unique among living tetrapods in that they possess a boxlike shell that is formed by dorsal and ventral parts (the carapace and plastron), which together cover most of the body of the animals. The carapace and plastron are of neural crest origin (Clark et al., 2001), deriving from vertebral and rib elements and lying superficial to both limb girdles (Burke, 1989). The turtle shell provides a significant measure of protection from predation and is involved in locomotory functions especially in adults (Erim et al., 2006).

A number of research reports on the shell morphology of chelonians had been documented. The shell morphology of the land tortoise, Testudo graeca Linnaeus, had been documented (Amiranashvili, 2000; Perala, 2001; Delfino et al., 2009). Also, shell morphology had been described in the Kemp's ridley, the Dermochelys and the Loggerhead (Wyneken, 2001) as well as in the Tropical tortoise chelonoidis denticulate (Manzano, 2009). The plastral morphology of four different subspecies of the Caspian turtle otherwise known as the stripedneck terrapin (Mauremys caspica) had also been reported (Tilman and Uwe, 1996).

There is scarcity of research information on the shell morphology of freshwater turtles of African origin. This study provides the first detailed osteological description of the carapace of the African sideneck turtle, which could be helpful in the identification of the turtle in paleontological and archaeological remains as well as in the comparative osteology of sea and freshwater turtles.

\section{Material and methods}

A total of 20 adult African sideneck turtles picked up at different times in 
various river banks in Ibadan, Nigeria, were used for the study. The animals were kept in artificial ponds and were stabilized for 72 hours prior to the investigations carried out. They were fed with commercial fish pellets ad libitum. Standard body parameters were all determined using a Draper® $115 \mathrm{~mm}$ vernier caliper and metric tape. The body weight of the animals was taken with the aid of a Microvar $®$ weighing balance. The turtles were anaesthetized using ketamine $\mathrm{HCl}$ at $25 \mathrm{mg} / \mathrm{kg}$ body weight intramuscularly at the medial aspects of the thigh muscle and then sacrificed by cervical decapitation. The preparation of skeletons of the animals was obtained through hot water maceration (Sommer and Anderson, 1974). The arrangement and number of scutes and bony elements of the shell were then investigated. Anatomical nomenclature used in the study followed the reports of Lapparent de Broin (2001) and Wyenken (2001).

\section{Results}

The average body weight of the turtles used for the study was $0.82 \pm$ $0.03 \mathrm{~kg}$. The curved carapace and plastron lengths were $26.4 \pm 1.87 \mathrm{~cm}$ and $19.3 \pm 1.13 \mathrm{~cm}$, respectively. The carapaces of the turtles used for the study were broadly oval caudally but blunt cranially; varying from dark brown to dark in colour.
The carapace had the following scutes: vertebral, costal or lateral, marginal and inframarginal. In all the turtles studied, the vertebral scutes were constantly five in number, flat in structure and medial in position overlaying the enclosed vertebrae of the animals (figure 1). In all the turtles studied, the second and third costal scutes matched up with the seventh marginal scute while the third and fourth costal scutes matched up with the ninth marginal scute. The first and last pairs of marginal scutes are in contact with the first and fifth vertebral scutes while marginals III to $X$ relate with the costal scutes medially.

The inframarginal scute formed the bridge between the carapace and plastron in each of the turtles. The bony elements of the carapace observed on each turtle were the nuchal bone, the neural bones, the pleurals, the suprapygal and pygal, the peripheral bones, and fused vertebrae. The nuchal bone relates with the first peripheral bone laterally and with the first pleural laterocaudally on both sides of the midseam of the plastron. Caudal to the nuchal bone were the neural bones, seven in number. The midlongitudinal series of neural elements were flanked on each side by a lateral costal series (pleurals), while a peripheral set of bones surround the pleurals (Figure 2). The 
carapace had eight pleurals expanding from each side of the neural series to the peripheral bones. The pleurals had the ribs and their dermal expansions while the peripheral bones formed the lateral margin of the carapace (figure 2).

The peripheral bones were eleven pairs, being separated cranially by the nuchal bone and caudally by the pygal bone. The 5th to 7th peripheral bones form the bridge (at the level of the inframarginal scute), the bony junction of the carapace and plastron. In each of the turtles, a triangular-shaped suprapygal bone was constantly found caudal to the sacral vertebrae and laterally related to the last (smallest) pair of pleural bones situated at the caudal portion of the carapace (figure 3 ). The suprapgal bone relates with the eighth pair of pleurals laterally, the third (last) sacral vertebra cranially and with the pygal bone caudally. The supracaudal portion of the pygal had a serrated edge in all the turtles. The lateral margins of the supracaudal were slightly concave and pointed in all the turtles (figure $3)$. Fused with the carapace on its ventral surface were the last cervical, 7 thoracic vertebrae and 3 sacral vertebrae. The sacral vertebrae were laterally related to the last pleurals on both sides of the median plane and presented with a flattened facet for the attachment of the dor- sal edge of the ilium to the carapace (figure 3).

\section{Discussion}

The colour, shape and structure of the carapace of the $P$. castaneus are similar to earlier reports on the shell morphology of the Pelusios species (Anderson, 1995; Broadley and Boycott, 2009). Different shapes of the carapace had been reported in the turtle: oval in Green turtle (Chelonia mydas), Hawsbill turtle (Eretmochelys imbricate), the Krefft's River turtle (Emydura macquarii krefftii), the genus Elseya and Flatback turtle (Natator depressus); heart-shaped in Black turtle (Chelonia species); and elongate in Leatherback turtle (Dermochelys coriacea) (Wyneken, 2001).

Like the African sideneck turtle, twelve pairs of marginal scutes had been reported in the pond turtle, Pangshura tatrotia (Joyce and Lyson, 2010). However, the carapace of the African sideneck turtle lacked keels unlike the pond turtle, Pangshura tatrotia (Joyce and Lyson, 2010). The number and arrangement of the scutes of the carapace of the African sideneck turtle is similar to those of the Sawshelled turtle (Myuchelys latisternum) with five vertebral scutes, four pairs of costal scutes, 12 pairs of marginal scutes with no nuchal scutes (Thomson and Georges, 
2009). Also, with the exception of the absence of nuchal scutes, the number and shape of vertebral, costal and marginal scutes on the carapace of the African sideneck turtle are similar to those of the Krefft's River turtle (Emydura macquarii krefftii) and the Fitzroy River turtle (Rheodytes leukops) (Georges and Thomson, 2010). The possession of five vertebral and four pairs of costal scutes had also been reported in the Green turtle (Chelonia mydas) and the Hawsbill turtle (Eretmochelys imbricate) whereas five vertebral and five pairs of costal scutes had been reported in the Kemp's ridley (Lepidochelys kempii) and the Loggerhead (Caretta caretta) (Wyneken, 2001). The anatomical dispositions whereby the second and third costal scutes match up with the seventh maginal as well as those of the third and fourth costal scutes matching up with the ninth marginal on the carapace of the African sideneck turtle is similar to that of the Saw-shelled turtle (Thomson and Georges, 2009). However, the second and third costal scutes match up with the sixth marginal while the third and fourth costal scutes match up with the eighth marginal in the Fitzroy River turtle (Thomson, 2000). The Olive ridley had been reported to have more than five normal vertebral scutes (apart from the irregular or super- numerary scutes usually present on the caparace) and usually six or more pairs of costal scutes (Wyneken, 2001).

The structure and arrangement of the bony elements of the carapace of the African sideneck turtle are similar to those reported in the Egyptian tortoise (Delfino et al., 2009); the Green turtle and Loggerhead (Wyneken, 2001; Ergene et al., 2011); and freshwater turtle Elseya dentate (Thompson et al., 2006). In all these turtles, the eighth cervical vertebra, the ribs and the dorsal vertebrae had been reported as being fused to the bony element of the carapace. However, the number of neural bones in the African sideneck turtle is less than that of Emys orbicularis which was reported as eight (Thompson and Georges, 2009). The number and arrangement of peripheral bones and the pleurals of the African sideneck turtle correspond to those of the pond turtle, Pangshura tatrotia (Joyce and Lyson, 2010). However, unlike the African sideneck turtle which has only one suprapygal bone, three suprapygal elements had been reported in the pond turtle, Pangshura tatrotia (Joyce and Lyson, 2010).

The basic anatomy of the carapace of the African sideneck turtle is similar to those of earlier reports on shell morphology of the chelonians 
(Amiranashvili, 2000; Wyneken, 2001; Perala, 2001; Delfino et al., 2009; Ergene et al., 2011; Nagashima, 2012). The information made available by this study is vital in the identification of the animal as well as in the comparative anatomy of the shells of both sea and freshwater turtles.

\section{Acknowledgement}

This work was supported by University of Ibadan Senate Research Grants (SRG/FVM/2010/4A and SRG/FVM/2010/1B).

\section{References}

Amiranashvili, N.G. (2000): Differences in shell morphology of Testudo graeca and Testudo hermanni, based on material from Bulgaria. Amphib.-Reptil. 21: 67-81.

Anderson, N.B. (1995): Life History notes: Pelusios castaneus: reproduction. African Herp News. 23:49.

Broadley, D.G., Boycott, R.C. (2009): Pelusios castaneus (Smith 1838) -Serrated Hinged Terrapin. Conservation Biology of Freshwater Turtles and Tortoises, Chelonian Research Monographs. 5: 036.1036.5 .

Burke, A.C. (1989): Development of the turtle carapace: implications for the evolution of a novel bauplan. J Morphol. 199:363-378.

Clark, K., Bender, G., Murray, B.P. (2001): Evidence for the neural crest origin of turtle plastron bones. Genesis 31:111-117.

Delfino,M.,Chesi,F.,Fritz,U.(2009): Shell morphology of the Egyptian tortoise, Testudo kleinmanni Lortet, 1883 , the osteologically least-known Testudo species. Zoological Studies 48(6): 850-860.

Ergene, S., Aymak, C., Uçar, A.H. (2011): Carapacial scute variation in green turtle (Chelonia mydas) and loggerhead turtle (Caretta caretta) hatchlings in Alata, Mersin, Turkey. Turk J Zool. 35(3) 343-356.

Erim, M. M., Fredric, J. J., Dean, C. A., John, K. T. (2006): Quantitative genetics of plastron shape in slider turtles (trachemys scripta). Evolution, 60(3), 563-572

Frazer, N. B. (2000): Forward. Pp xi-xiv. In M. W. Klemens (Ed.), Turtle Conservation. Smithsonian InstitutionPress, Washington,D.C.,U.S.A.

Georges, A., Thomson, S. (2010): Diversity of Australasian freshwater turtles, with an annotated synonymy and keys to species. Zootaxa 2496: 1-37. 
Gilbert,S.F.,LoredoG.A.,Brukman, A.,Burke, A.C. (2001): Morphogenesis of the turtle shell: the development of a novel structure in tetrapod evolution. Evol Dev. 3:47-58.

Joyce, W.G., Lyson, T.R.(2010): Pangshura tatrotia, a new species of pond turtle (Testudinoidea) from the Pliocene Siwaliks of Pakistan. Journal of Systematic Palaeontology. (8) 3, 2010, 449-458.

Kirkpatrick, D. T. (1995): An Essay on Taxonomy and the Genus Pelusios. Available at: http:// www. unc.edu/ dtkirkpa/stuff/pel.html. Accessed 22 February 2013.

Lapparent, de Broin F de. (2001): The European turtle fauna from the Triassic to the present. Dumerilia 4: 155-217.

Manzano,A.S.,Noriega, J.I., Joyce, W.G. (2009): The Tropical tortoise chelonoidis denticulate (testudines: testudinidae) from the late Pleistocene of Argentina and its paleoclimatological implications. J.Paleont. 83(6), 975-980 .

Nagashima,H., Kuraku S., Uchida, K., Kawashima-Ohya, Y., Narita, Y., Kuratani, S. (2012): Body plan of turtles: an anatomical, developmental and evolutionary perspective. Anat Sci Int. 87:1-13.
Olukole,S.G.,Aina,O.O.,Okusanya, B.O. (2010): Morphometric analysis of the external body anatomy of the African sideneck turtle (Pelusios castaneus). Book of abstracts of the $30^{\text {th }}$ Annual Symposium on Sea Turtle biology and conservation held in Goa, India. 265.

Perala, J. (2001): A new species of Testudo (Testudines: Testudinidae) from the Middle East with implication for conservation. J. Herpetol. 35: 567-582.

Sommer,H.G.,AndersonS., (1974): "Cleaning skeletons with dermestid beetles - two refinements in the method", Curator. 17, (4), 290-298.

Thompson, S.,Georges, A., Limpus, C.J. (2006): A New Species of Freshwater Turtle in the Genus Elseya (Testudines: Chelidae) from Central Coastal Queensland, Australia. Chelonian Conservation and Biology. 5(1): 74-86

Thomson, S. (2000): A Revision of the Fossil Chelid Turtles (Pleurodira) Described by C.W. De Vis, 1897. Memoires of the Queensland Museum 45(2):593-598.

Thomson, S., Georges, A. (2009): Myuchelys gen. nov. - a new genus for Elseya latisternum and related forms of Australian freshwater turtle 
(Testudines: Pleurodira: Chelidae) Zootaxa. 2053: 32-42.

Tilman, W., Uwe, F.J. (1996): Eine neue Unterart der Bachschildkröte (mauremys caspica ventrimaculata subsp. nov.) aus dem Iranischen Hochland (A new subspecies of the Caspian turtle (Mauremys caspica

* Corresponding Author

E-mail : deborolukole@yahoo.com sg.olukole@mail.ui.edu.ng

Phone number: +2348033574752 ventrimaculata subsp. nov.) from the Iranian Highlands). Salamandra. 32 (2), 113-122.

Wyneken, J. (2001): The Anatomy of Sea Turtles. U.S. Department of Commerce NOAA Technical Memorandum NMFS-SEFSC. 470, 1-172.

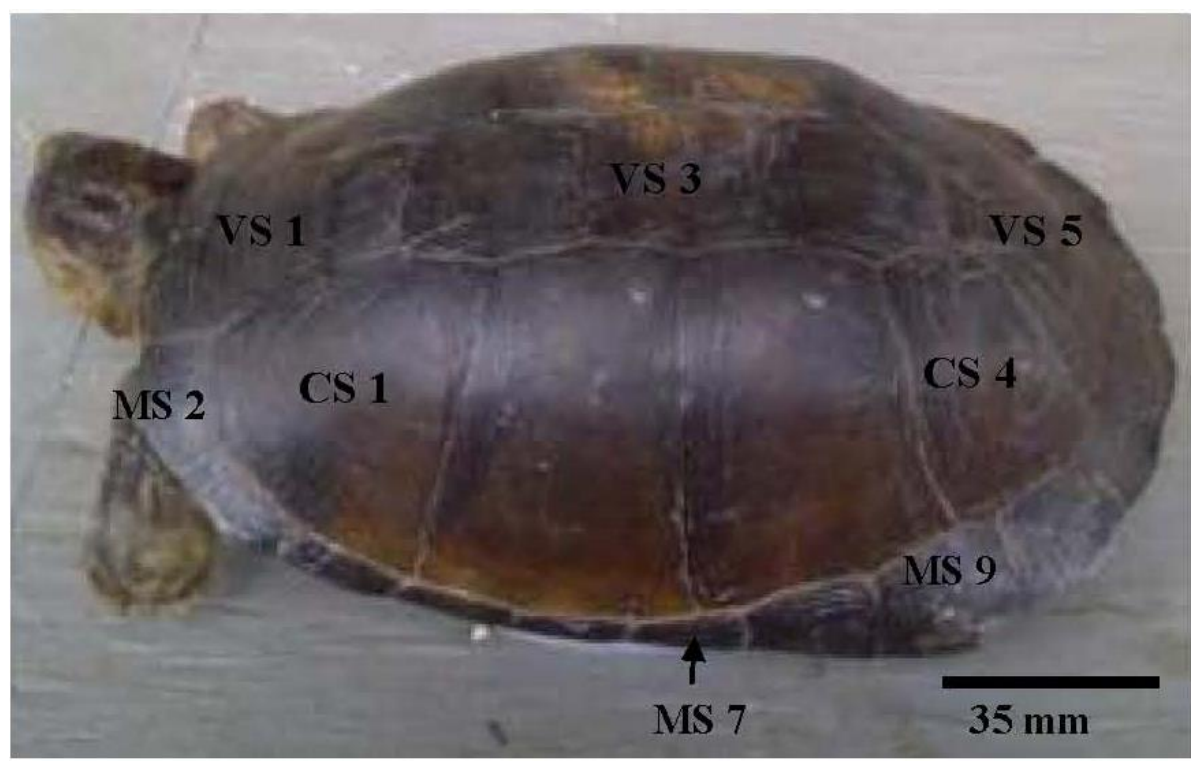

Fig (1): Dorsolateral view of the shell of the African sideneck turtle. VS 1: First vertebral scute; VS 3: Third vertebral scute; VS 5: Fifth vertebral scute; MS 2: Second marginal scute; MS 7: Seven marginal scute; MS 9: Ninth marginal scute; CS 1: First costal scute; CS 4: Forth costal scute. 


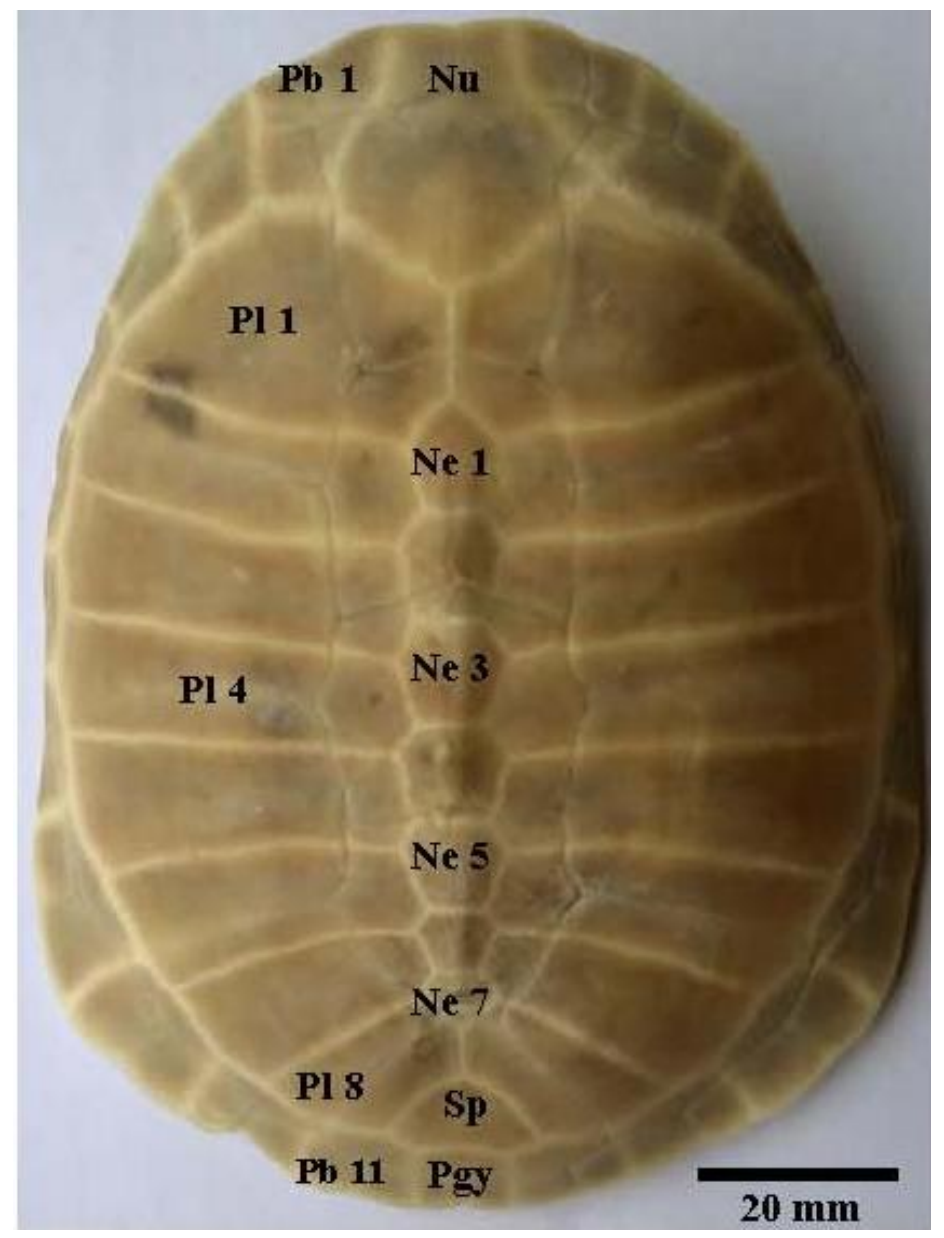

Fig (2): Bony components of the carapace of the African sideneck turtle (Pelusios castaneus). Nu: Nuchal bone; Pb 1- Pb 11: First to eleventh peripheral bone; $\mathrm{Ne} 1-\mathrm{Ne}$ 7: First to seventh neural bone; PI 1- PI 8: First to eighth pleural; Sp: suprapygal bone; Pgy: pygal bone. 


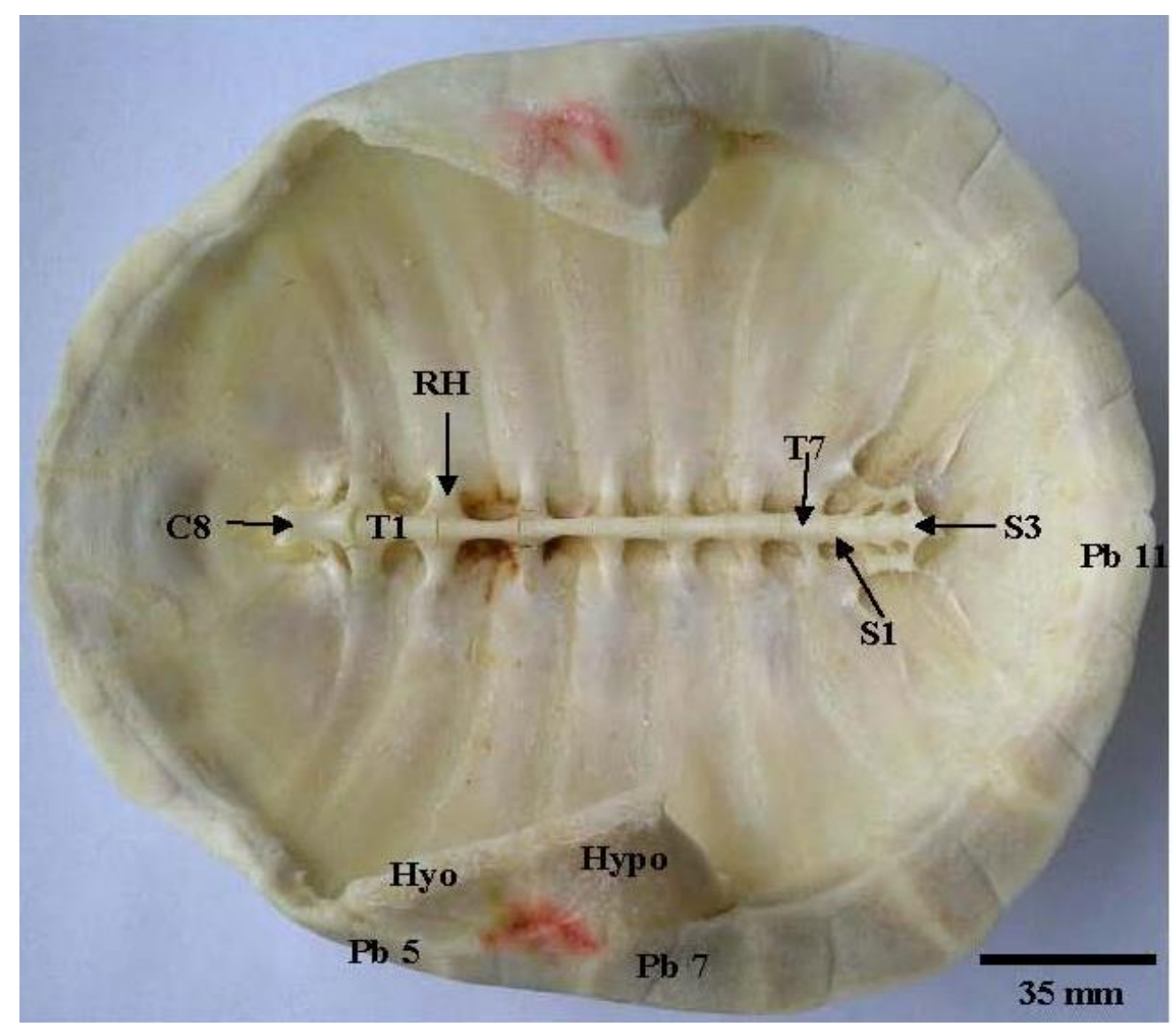

Fig (3): Ventral view of the bony components of the carapace of the African sideneck turtle. Nu: Nuchal bone; C8: Eighth cervical vertebra; T1 - T7: First to seventh thoracic vertebra; Rh: head of rib; S1 - S3: First to third sacral vertebra; Pb 5 to Pb11: Fifth to eleventh peripheral bone; Hyo: Hyoplastron; Hypo: Hypoplastron. 